\title{
KRONIKA
}

MARIA M. BOUŻYK

Wydział Nauk Pedagogicznych

Uniwersytet Kardynała Stefana Wyszyńskiego

ORCID ID: http://orcid.org/oooo-ooo1-8887-2521

Forum Pedagogiczne
9 (2019) 1

Wpłynęło: 17.02.2019

Zatwierdzono do druku: 24.04.2019 DOI: $10.21697 / \mathrm{fp} .2019 .1 .21$

\section{"Evaluation of Humanistic Competencies Developed in the Pedagogical Majors in a Comparative Perspective": Project Overview}

This overview presents actions taken in the first year of a three-year collaborative international project implemented by research teams from the Faculty of Education of the Cardinal Stefan Wyszyński University in Warsaw (the FE UKSW) and the Faculty of Education of Catholic University in Milan (the FE UCSC). The basis of the cooperation was a bilateral agreement signed by the two universities. The project plan was developed by the Polish side. It received an annual funding from grants for maintaining the potential from the pool of scientific cooperation with foreign countries (UmoPBNP-17/18). The Italian team included Giuseppe Mari (team leader), Marisa Musaio and Simonetta Polenghi. The Polish team consisted of Maria M. Boużyk (team leader), Stanisław Chrobak, Jan Piskurewicz, Witold Starnawski, and Dariusz Stępkowski. The implementation of the project was suspended due to the sudden death of the leader of the Italian team and changes in the financing of scientific research in Poland (Act 2.0). Nevertheless, it is worth documenting the activities carried out and the results achieved.

\section{The planned cooperation}

The aim of the cooperation undertaken within the framework of the project (hereinafter called the Project) was to compare the humanistic competences acquired by students in the pedagogical majors of the two universities (the UKSW and UCSC) with reference to European standards of academic education designated by the Bologna Declaration. The use of the word "competence" as a tool to describe the qualifications of students of Pedagogy in the area of humanities was considered compatible with the terminology used in the European Higher Education Area (EHEA) and the EU policy on education: supporting the personal development of students and preparing them for professional work, civic life, and active participation in the creation of a society of knowledge (Chmielecka, 2014). Therefore, courses were selected that, in the opinion of the researchers, 
can contribute in a special way to the development of humanistic competences in student of Pedagogy. They comprised general pedagogy, philosophy, ethics, Christian pedagogy, and the history of pedagogical theory.

The choice of subjects included in the project was intentional. Members of the teams cared primarily about defying two tendencies that were recently noted in the academic teachers' training. They were especially concerned about (1) limiting programs to a professional preparation, excluding humanistic preparation and (2) narrowing humanistic education to psychology or sociology. Two items related to the educational programs of the participating universities were also taken into account, which mark the model of humanism implemented in them with Christian values, i.e. Christian pedagogy (the FE UKSW) and theology (the FE UCSC).

The project was divided into three parts planned for implementation in the years 2018-2020. In the first year, characteristics of humanistic competences developed in the respective Schools of Pedagogy were to be established; in the second year research design and a pilot study of the said competences among students of both faculties were drafted; and the last stage of the project was to compile the main study and do a comparative analysis of the collected material. A comparative publication was to be the culmination of the research, while as its practical application we envisioned a proposal to possibly modify the humanities training programs at each facultyaccording to the individual needs of the two universities.

\section{Implementation of the first stage of the project}

The project was carried out simultaneously at both universities. The Polish team would meet once a month between January and November 2018. Two of the four working meetings planned for 2018 were held with the Italian partner (the FE UCSC represented by prof. G. Mari): the first (25/01/2018) concerned cooperation and how to conduct research by both teams (among others, specialisations for comparative research, i.e. special education as well as preschool and primary education were selected), and the second (29/05/2018) dealt with comparing the curricula of both faculties in the aforementioned specialisations in the field of selected humanities.

However, because of the unfortunate circumstances, the other two meetings did not take place. One of them was planned at the FE UKSW on $27 / 11 / 2018$, on defining humanistic competences developed by the Polish partner and on the designation of research areas, and the other was to be held at the UCSC in Milan, regarding the comparison of educational content from selected humanities. 


\section{Research results}

The results of the Project's implementation in 2018 will be presented below in three sections.

\section{Selection of educational areas for comparative research}

Due to the fact that the majors at the two faculties are not identical, two convergent areas were selected: special education, preschool and primary education. Even though both the FE UKSW and FE UCSC offer studies in these areas, each faculty implements them within the framework of a university-specific structure of study. ${ }^{1}$

At the FE UCSC, studies in the field of preschool and primary education are majors offered as a continuous 5-year program (name of the course is Infant / Primary School Teacher). However, studies at the FE UKSW are two-staged (3-yearBA and 2-year MA) and constitute one of the three specialisations of the Education majors. Differences in the structure of studies are also noticeable in the field of special education. At the FE UKSW it is a separate course with three specialisations and the studies last 3 years (BA). However, at the FE UCSC the studies (Specialisation for Didactic Support to Students with Disabilities) last 8 months, and with the evaluation phases they extend to 12 months.

\section{Comparison of humanities programs at the two faculties}

Our teams compared the respective curricula. We looked at the content of study modules, the number of hours of selected humanities in relation to the total number of study hours, divided into individual years and stages of study (BA and MA), ECTS points, grades, forms of classes, rules for obtaining a diploma and the content of education. This report presents only conclusions on the number of hours in the field of selected humanities in the curricula. It should also be noted that a comparative analysis of the content of education of selected humanities could not be carried out. Only data collected by researchers from the FE UKSW were available, whereas no information was obtained from the FE UCSC because the project needed to be terminated prematurely.

At the FE UKSW there is one humanistic program (in the scope of distinguished courses). The number of hours of these courses is 240 per each stage of studies (BA and MA) - a total of 480. They constitute part of the total number of hours of study, which are as follows: Bachelor's - $1950 \mathrm{~h}$, Master's $-1285 \mathrm{~h}$. Whereas at the FE UCSC the number of courses and hours of classes in the field of humanities depends on

1 In 2018, at FE UKSW there were two majors (Education; Special Education), and on each of them 3-4 specialties. There are a total of four majors at the FE UCSC: Special Education, Infant / Primary School Teacher, and Physical Education Sciences and Education (with 4 specialisations). 
the curriculum, while in each curriculum a module of classes related to theology is required. Within the Infant / Primary School ("Science della formazione primaria") curriculum humanistic courses such as General Pedagogy (6o hours), or History of School and Educational Institutions (6o hours) are in the first year of studies. During a 5-year program, students have several electives to choose from (6o hours), e.g. Paradigms and styles of the philosophical thought (6o hours).

It has been noticed that philosophy classes are more developed at the FE UKSW. They consist of Philosophical Foundations of Pedagogy and Education (lectures $30 \mathrm{~h}$; tutorials $3 \mathrm{O}$ h) and Pedagogical Ethics (lectures $30 \mathrm{~h}$ ) - both in the first year of BA studies. In addition, during the two years of MA studies students are offered the following lectures: Present Philosophical and Ethical Tendencies in Education (30 h;) and Philosophy of Education (30 h). In total, there are $150 \mathrm{~h}$ at the FE UKSW compared to $6 \mathrm{o}$ h at the FE UCSC. This proportion is further increased in favour of the FE UKSW due to the fact that a large load of philosophical content is present in the following lectures at the FE UKSW: Pedagogy of the Person (15 h of lectures) and Anthropology of Culture (3o h of lectures).

The number of hours of other humanities is similar in both universities in terms of History of Educational Theory (6o h) and General Pedagogy (6o h). Besides, both universities offer lectures on the content, recognized by the research teams of both universities, significant for educating the humanistic competence of educators. The Polish team included the following lectures: Selected Problems of Pedagogical Studies ( $30 \mathrm{~h}$ ) and Education-Morality-Democracy ( $30 \mathrm{~h}$ ). The Italian team mentioned the following lectures in the studies of Infant / Primary School: Special Pedagogy (6o h) and Social and Intercultural Pedagogy (6o hours). But in the major of Specialization for Didactic Support to Students with Disabilities, due to the specificity of the study model (8-12 months), the team pointed out the humanistic content in a variety of vocational training courses.

\section{The problem of defining humanistic competences}

It was initially established that humanistic competences (HC) of educators are a transfer of knowledge acquired during the education for professional (pedagogical) practice and that they combine three areas of activity: humanistic knowledge (HK), humanistic thinking (HT) and humanistic activity (HA). Therefore, one can interpret them as "qualitative change in a human being". The twofold understanding of the term "knowledge" proved to be helpful in this interpretation. Knowledge can be interpreted as a set of contents in a given field that can be attributed to a professional activity, e.g. ethics to the profession of a teacher; we also understand knowledge as an achievement of a certain degree of intellectual culture resulting from education, and manifested by creative (free, non-schematic) thinking used in professional work. We could describe it as humanistic thinking 
(HT), e.g. examining certain pedagogical situations encountered by an educator in a professional life from an ethical perspective.

The former understanding highlights the objective aspect of knowledge/ cognition (we learn about reality in its various aspects, and the expression of this are the scientific theories, the network of concepts and specialist language), whereas the latter understanding emphasises the subjective aspect of scientific knowledge (cognition/knowledge that perfects/transforms the person). The subjective aspect of scientific knowledge is important for competences. Its application to the education process lets perceive this process as an "event" between two participants, a lecturer and a student. This term coincides with the formal way of determining the student's level of competences (qualifications) (including education courses and diplomas) within the EQF/NQF, i.e. with the K-S-C (knowledge - skills - competence) descriptors and the differentiation of learning objectives from the skills acquired by the student in the process of education (learning outcomes), described with these descriptors. Therefore, it was decided to apply this formal method of determining competence in the examination of $\mathrm{HC}$ of the students of Pedagogy. In the humanistic education of educators, not only the goals that have been set are at stake but also the real outcomes of education. They can be expected as the efficiency of humanistic thinking in the professional life of graduates of both faculties, i.e. not only through the use of knowledge as content but also in the fact that this content will be used and that it can be tailored to the needs that arise in a specific professional situations.

\section{An attempt to determine diagnostic areas}

While attempting to identify diagnostic areas (hereinafter DA) in which $\mathrm{HC}$ can be subject to observation and analysis, the teams used the aforementioned categories of learning objectives (LOBs), learning outcomes (LOs), and above all, the K-S-C descriptors together with the levels of education (1-8). It was assumed that the determination of diagnostic areas would allow identifying $\mathrm{HC}$ and revealing their complexity and relevance to professional activities of graduates of pedagogical studies. Since the phenomenon of competence is related to the applicability of knowledge, and also while there is a relationship between knowledge, thinking, and action (and its output), it was assumed that in the case of HC such a relationship also exists (HK-HT-HA), and the effects of students' activities of both faculties may also be the subject of research. Three diagnostic areas were distinguished. The first one concerned humanistic knowledge (DA1), the second - humanistic thinking (DA2), and the third - humanistic activities (DA3).

The first diagnostic area (DA1) is designated by the relation of professional competences included in the description of the so-called "graduate profile" to humanistic knowledge $(\mathrm{HK})$. The Bologna Process emphasizes the scope and depth of information (EQF/NQF - K descriptor); therefore, distinguishing the area of humanistic knowledge and its relation to professional competences 
seems to be justified. It was noted that when studying $\mathbf{H K}$, attention should be drawn to the differentiation between learning objectives and learning outcomes. The subjective dimension of knowledge referring to the LOs factor is expressed in the K-S-C descriptors attributed to the course. The LOBs factor can be defined by a set of objectives in teaching and methods of their implementation. Both factors are included in the syllabi of the academic education program.

The analysis of syllabi and "graduate profiles" would focus on looking for answers to the following three questions:

1. What is the relationship between professional competences in the description of the so-called "graduate profiles" and the learning objectives/learning outcomes in the field of HK in both faculties? The study would involve the interpretation of a $\mathrm{K}$ descriptor (knowledge) limited to HK (humanistic knowledge) in the context of professional competences in the description of the so-called "graduate profiles" at the FE UKSW / FE UCSC, taking into account the learning outcomes chart in the field of humanities for the first/second cycle of studies.

2. What is the relationship between $\mathrm{HK}$ and $\mathrm{HC}$ of the students in both faculties as far as learning objectives and learning outcomes are concerned? The study would involve interpreting the $\mathrm{K}$ descriptor(knowledge) in the context of the selected humanities subjects and descriptors of learning outcomes of these subjects.

3. Is the acquisition of humanistic knowledge in both faculties expressed in the correct correlation of ECTS credits with the student's workload (e.g. how much time will the student spend on reading the scientific literature)? In accordance with the recommendations of the Bologna Process, ECTS points are another, apart from the descriptors, record of the student's competences.

The second diagnostic area (DA2) is defined by the relation between particular types of humanistic knowledge and humanistic pedagogical thinking in the field of analysed specialisations. Interdependence of the content of humanistic education in the field of selected courses should be taken into account, and then a comprehensive test for students of the last year of studies (BA, MA) should be prepared. This is important in so far as there is a need for multidisciplinary education (and doing scientific work in "adjacent" areas), whereas pedagogical studies are, by their very nature, multidisciplinary today. The Bologna Process guidelines also give the student the opportunity to pursue an individual learning path. However, widening the cognitive horizons, which is supposed to be a consequence of such educational activities, may be deceptive due to the threat of shallow knowledge and the freedom to combine different areas of knowledge. Without the opportunity to thoroughly learn the secrets of methodology, a graduate in education will get a "distorted" image, e.g. of an integrated anthropology important for pedagogical activities. Such a person duplicates learning patterns obtained from high school rather than creatively participates in the process of acquiring knowledge, which 
according to the Bologna Process should be expressed in efficiency and independence (EQF/NQF - S descriptor).

It was also proposed to interpret HC in terms of HT (humanistic thinking) in light of all eight levels of EQF, because the quality of didactic work with students is conditioned by their intellectual culture obtained from high school. An extension of the study in this area would involve the preparation of an analogous test for first-year students, so as to compare humanistic thinking "on entry" (HT1) and "on exit" (HT2).

The third area $\left(\mathrm{DA}_{3}\right)$ that required attention in the determination of $\mathrm{HC}$ because of the descriptor of "social competence" $(\mathrm{C})$, concerns the moral attitudes of students towards the responsibilities that arise from studying. It can be assumed that the attitudes (ethos) of students, manifested in their relation to the duties resulting from belonging to the academic community, will one day translate into their professional activities. Moral competences are revealed, among others, in the responsibility for the chosen path of education. The research methodology the students apply to humanistic subjects can show a lot here (e.g. reliability of source selection, adherence to the recommendations of teaching staff, attendance at classes, preparation for classes, the level of examinations).

Translated by Agnieszka Burakowska

\section{References}

Chmielecka E. (2014). Proces Boloński - za i przeciw. "Nauka Polska”, No. 23, pp. 11-38. 